Robert D. Elliott MD FRCPC

\title{
Continuous infusion epidural analgesia for obstetrics: bupivacaine versus bupivacaine- fentanyl mixture
}

Continuous infusion epidural analgesia (CIEA) using a mixture of bupivacaine and fentanyl was evaluated in this randomized. double-blind study involving 75 nulliparous women by comparing the mixture (Group I, Bupivacaine 0.125\% and fentanyl 4 $\mu \mathrm{g} \cdot \mathrm{ml}^{-1}-24$ patients) with two concentrations of bupivacaine alone (Group 1I, bupivacaine 0.25\% - 24 patients; and Group III. bupivacaine $0.125 \%-27$ patients). Epidural anaesthesia was established in Group I with $6 \mathrm{ml} 0.125 \%$ bupivacaine with fentanyl $50 \mu \mathrm{g}$ and in both Groups II and III with $6 \mathrm{ml} 0.25 \%$ bupivacaine. In the women whose pain score (Visual Analogue Scale) decreased by at least $50 \%$ within $15 \mathrm{~min}$, CIEA was given until delivery. The initial infusion rate in all three groups was set at $7 \mathrm{ml} \cdot \mathrm{hr}^{-1}$, but was decreased in the event of motor block or excessive sensory level. For inadequate analgesia, bupivacaine $0.25 \%$ in $3 \mathrm{ml}$ supplements was given every $30 \mathrm{~min}$. as required. During the first stage of labour, $88 \%$ of women in Group I reported excellent or good analgesia compared with $92 \%$ of women in Group $I(N S)$ and with 59\% in Group $I I(P<$ 0.05 ). The proportion of women reporting excellent/good analgesia during the second stage was approximately $65 \%$ in all three groups. The total cumulative dose of bupivacaine in Group I was $54 \pm 36 \mathrm{mg}$, compared with $107 \pm 47 \mathrm{mg}$ for Group II $(P=0.001)$, and $7 I \pm 4 I \mathrm{mg}$ for Group III (NS). Group I patients required less supplementation with bupivacaine than

\section{Key words}

ANAESTHESIA: obstetric;

ANAESTHETIC TECHNIQUES: epidural;

ANAESTHETIC, LOCAL: bupivacaine;

ANALGESICS: fentanyl.

From the Department of Anaesthesia, Ottawa General Hospital, University of Ottawa.

Address correspondence to: Dr. R.D. Elliott, Department of Anaesthesia, Ottawa General Hospital, 501 Smyth Road,

Ottawa, Ontario K1H 8L6.

Presented at the Canadian Anaesthetists' Socicty 47 th Annual Meeting, Vancouver, British Columbia, June 1990.

Accepted for publication 3rd December, 1990. either Group II or III patients during the first stage but only with Group III patients during the second stage. Patients in Group I were less likely to develop motor block than parients in Group II, $(P<0.05)$. It is concluded that the bupivacaine $0.125 \%$ combined with fentanyl (4 $\left.\mu \mathrm{g} \cdot \mathrm{ml}^{-1}\right)$ infusion provided analgesia more effectively than either bupivacaine $0.25 \%$ or $0.125 \%$ alone during the first stage, or bupivacaine $0.125 \%$ alone during the second stage. Continuous infusion epidural analgesia with the bupivacaine-fentanyl mixture protocol of this study will provide good analgesia during the first stage of labour and adequate analgesia during the second stage, without altering spontaneous delivery rates or neonatal outcomes.

La perfusion continue pour l'analgésie épidurale (CIEA) utilisant un mélange de bupivacaïne et de fentanyl fut évaluée dans. cette étude randomisée à double insu, sur 75 femmes nullipares en comparant le mélange (Groupe 1 , bupivacaïne $0.125 \%$ et fentanyl $4 \mu \mathrm{g} \cdot \mathrm{ml}^{-1}-24$ patientes) avec deur concentrations de bupivacaïne seule (Groupe II, bupivacaine $0.25 \%-24$ patientes; et Groupe III, bupivacaine 0.125\% - 27 patientes). $L$ 'anesthésie épidurale fut établie dans le Groupe 1 avec $6 \mathrm{ml}$ $0.125 \%$ de bupivacane avec fentanyl $50 \mu \mathrm{g}$ et dans les Groupes II et III avec $6 \mathrm{ml} 0.25 \%$ de bupivacaine. Chez les femmes chez qui le score de la douleur (Visual Analogue Scale) a diminué d'au moins 50\% à l'intérieur de 15 minutes, la CIEA fut administrée jusqu'à l'accouchement. Le taux de perfusion initiale dans les trois groupes fut établie à $7 \mathrm{ml} \cdot \mathrm{hre} \mathrm{e}^{-1}$, mais fut diminué dans les cas de blocage moteur ou d' un niveau sensoriel excessif. Pour l'analgésie inadéquate, la bupivacaïne $0.25 \%$ en supplément de $3 \mathrm{ml}$ fut administrée d̀ toutes les 30 minutes selon la nécessité. Durant la première érape du travail. $88 \%$ des fermmes du Groupe I ont rapporté une analgésie bonne ou excellente comparativement avec $92 \%$ des femmes du Groupe II (NS) et avec 59\% du Groupe III $(P<0.05)$. La proportion des femmes ayant rapporté une analgésie bonne à excellente durant la deuxième étape fut approximativement de $65 \%$ dans tous les trois groupes. La dose totale cumulative de bupivacaïne dans le Groupe létait de $54 \pm 36 \mathrm{mg}$, comparé à $107 \pm 47 \mathrm{mg}$ pour le Groupe II $(P=0.00 I)$, et $7 I \pm 4 I \mathrm{mg}$ pour le Groupe III (NS). 
Les patientes du Groupe I ont requis moins de dose supplémentaire avec bupivacaine que les Groupes II ou III durant la première étape mais uniquement aux patientes du Groupe III durant la deuxième étape. Les patientes du Groupe I étaient moins susceptibles de développer un blocage moteur que les patientes du Groupe II $(P<0.005)$. On conclut que la bupivacaine $0.125 \%$ combinée au fentanyl $\left(4 \mu \mathrm{g} \cdot \mathrm{ml}^{-1}\right)$ en perfusion fournit une analgésie plus efficace que la bupivacaïne seule à des doses de $0.25 \%$ ou $0.125 \%$ duram la première ètape, ou la bupivacaïne à $0.125 \%$ seule durant la deuxièmé étape. L'analgésié épidural par perfusion continue avec un mélange de bupivacaïne-fentanyl dans cette étude fournira une bonne analgésie durant la première étape et une analgésie adéquate durant la seconde étape sans altérer les taux d'accouchement spontané ou les issues méonatales.

Continuous infusion epidural analgesia (CIEA) with bupivacaine became widely used in the 1980s. Good analgesia was reported with various concentrations of bupivacaine using a range of infusion rates. ${ }^{1,2.3}$ Recent concerns with the CIEA technique centre on the relatively high total bupivacaine dosage and the suggestion of a decrease in the rate of spontaneous delivery. ${ }^{4}$ Altering the CIEA technique by discontinuing the infusion at full dilatation or even at $8 \mathrm{~cm}$ dilatation has resulted in improved spontaneous delivery rates but at the expense of inadequate analgesia during the second stage of labour. ${ }^{5}$

One of the important developments in the past decade has been the epidural administration of an opioid, alone or in combination with a local anaesthetic. It was found that the addition of an opioid allowed a reduction in the dose of local anaesthetic while maintaining adequate analgesia. ${ }^{6-9}$ Chestnut et al. ${ }^{10}$ reported that, when compared with $0.125 \%$ bupivacaine, a mixture of $0.0625 \%$ bupivacaine $/ 0.0002 \%$ fentanyl $\left(2 \mu \mathrm{g} \cdot \mathrm{ml}^{-1}\right)$ infused at $12.5 \mathrm{ml}$. $\mathrm{hr}^{-1}$ (equivalent to an hourly rate of $7.8 \mathrm{mg}$ bupivacaine and $25 \mu \mathrm{g}$ fentanyl) produced similar analgesia, but with less intense motor block and no change in the duration of the second stage of labour or spontaneous delivery rate. In this study fentanyl was limited to an initial dose of $50 \mu \mathrm{g}$ and infusion of a further $100 \mu \mathrm{g}$ over four hours for a total of $150 \mu \mathrm{g}$. The epidural infusion was discontinued at full cervical dilatation, in an attempt to prevent a possible decrease in the spontaneous delivery rate.

Since 1983 our institution has used bupivacaine $0.25 \%$ at an infusion rate of $7 \mathrm{ml} \cdot \mathrm{hr}^{-1}\left(17.5 \mathrm{mg} \cdot \mathrm{hr}^{-1}\right)$ to provide analgesia for first and second stages of labour. Usually the epidural infusion is continued until delivery although the rate may need to be decreased because of lower limb motor block. The present study had two purposes. The first was to investigate the ability of an epidural bupivacaine-fentanyl infusion to provide good analgesia with little motor block, using similar masses of bupiva- caine and fentanyl as studied by Chestnut et al. but in a more concentrated form. A mixture of $0.125 \%$ bupivacaine combined with fentanyl $4 \mu \mathrm{g} \cdot \mathrm{ml}^{-1}$ (equivalent to an hourly rate of $8.75 \mathrm{mg}$ bupivacaine and $28 \mu \mathrm{g}$ fentanyl) was chosen and the study was designed for two independent comparisons with fentanyl-free infusions of $0.25 \%$ and $0.125 \%$ bupivacaine. The second goal was to continue the infusions to delivery and assess the effect on analgesia during the second stage of labour and on the mode of delivery.

\section{Methods}

The protocol was approved by the institutional review board for human research. Written informed consent was obtained from 90 nulliparous women with singleton fetuses in vertex presentation and gestation greater than 36 wk and with cervical dilatation between 3 and $7 \mathrm{~cm}$. An ASA physical status greater than I or II, or an abnormal fetal heart rate recording resulted in exclusion from the study.

Patients were allocated in a blinded, random fashion to one of three treatment groups. A colleague not involved with either the performance or evaluation of the epidural anaesthetic prepared sets of syringes numbered sequentially by referring to a computer-generated randomization table. Each set of syringes was labelled by patient number and by an alphabetic character. A $10 \mathrm{ml}$ syringe labelled as study solution " $A$ " contained $6 \mathrm{ml}$ of drug for the establishment of the epidural: Group I received $0.125 \%$ bupivacaine plus fentanyl $50 \mu \mathrm{g}$ while Groups II and III received $0.25 \%$ bupivacaine plain. A $50 \mathrm{ml}$ syringe labelled as study solution " $B$ " contained $50 \mathrm{ml}$ of drug for the maintenance epidural infusion: Group I received $0.125 \%$ bupivacaine with fentanyl $4 \mu \mathrm{g} \cdot \mathrm{ml}^{-1}$; Group Il received $0.25 \%$ bupivacaine; Group III received $0.125 \%$ bupivacaine.

Each patient received an iv fluid bolus of $500 \mathrm{ml}$ Ringer's lactate over 15-20 min prior to establishment of the epidural block. The preferred site was the $\mathrm{L}_{2-3}$ interspace and a catheter was advanced craniad approximately $3-4 \mathrm{~cm}$. Prior to the injection of a test dose, the patient was asked to indicate the intensity of her pain on a $100 \mathrm{~mm}$ scale (Visual Analogue Scale: $0=$ no pain, $100=$ worst possible pain), demarcated in $10 \mathrm{~mm}$ segments. With "time-zero" noted, all patients in all three groups then received the same test dose (lidocaine $1.5 \%$ with epinephrine 1:200,000). Five minutes later, after assessment of the patient, the anaesthetist gave solution " $A$ " $(6 \mathrm{ml})$ to establish the epidural block. At zero-plus- $20 \mathrm{~min}$, the pain score was again determined. If the score had decreased by $50 \%$ or more, the epidural was considered successful, and the infusion of solution " $B$ " was begun, using an IVAC Model 700 syringe pump set at $7 \mathrm{ml} \cdot \mathrm{hr}^{-1}$. If the 
decrease in pain score did not meet this criterion, the epidural was considered a technical failure. Patients with failed epidurals did not participate further in the study; a patient number allocated to such a patient was not re-allocated.

The patients were assessed by experienced case-room nurses every 30 min until delivery. With each assessment a pain score was determined. In addition, the dermatomal height of the block and the presence of motor block (score 0-3: none, partial, almost complete, complete) were recorded along with maternal blood pressure and heart rate, fetal heart rate abnormalities, the use of oxytocin and the presence of complications such as nausea, vomiting, pruritus and urinary retention. At full cervical dilatation and again immediately after delivery, each patient was asked to assess the quality of the analgesia provided by the epidural block, as excellent, good, fair, or poor. Neonatal outcome was assessed by Apgar score and timeto-sustained-respiration.

The epidural infusion rate in all groups was kept constant as much as possible throughout the first stage of labour. If motor block (score $>1$ ) developed, the rate was decreased, usually to $4 \mathrm{ml} \cdot \mathrm{hr}^{-1}$. Increasing the rate was not permitted. At each $30-\mathrm{min}$ assessment, if patients complained of inadequate analgesia, the infusion was supplemented with a 3 -ml bolus of $0.25 \%$ bupivacaine. At the time of delivery, if perineal anaesthesia was inadequate, carbonated lidocaine $2 \%$ was permitted, using a dose at the discretion of the attending anaesthetist.

Statistical analysis compared separately the data from Group I, the study group, with data from each of the two controls, Groups II and III (i.e., Group I versus Group II and Group I versus Group III). This decision to limit the study a priori to two of the three possible comparisons, eliminated the necessity for post hoc multiple comparisons procedure and the reduction of the $\alpha$ value for each comparison. ${ }^{11}$ Patient demographic data, labour and infusion durations, bupivacaine administration and neonatal weights were compared using Student's t test. The frequencies of the modes of delivery and the patient assessments of analgesia, as well as the incidences of infusion interventions, motor block scores greater than zero and APGAR scores greater than or equal to seven were compared with the Chi-square or Fisher exact tests, as required. Analysis of the VAS scores by a repeatedmeasures analysis-of-variance procedure was not possible because patients with shorter labours had fewer pain scores resulting in "missing values" for many of the 30-min assessments. Since the study was primarily investigating the efficacy of the technique overall and not at any specific time point, the pain scores of an individual patient over a time interval were transformed into a single summary score. This data transformation is valid when the average duration of the chosen time interval is similar in the two groups being compared. As the VAS scores were not normally distributed, but were skewed to the lower end of the scale, Bartlett's test on the variances of the data recommended using non-parametric analysis Therefore, the median was chosen to summarize each patient's VAS scores in a particular time interval and the summary scores were compared using the Mann-Whitney test. Because the patients arrived at full dilatation at differing times relative to epidural insertion, the VAS and bupivacaine data were expressed as well using the time relative-to-full-dilatation (with time intervals first and second stages of labour) in order to separate any cumulative effects resulting from longer bupivacaine infusions from the effect of the transition from first to second stage of labour. The motor block data were examined for a positive correlation between the duration of the infusion in minutes and the incidence of patients with motor block scores greater than zero, using multiple regression analysis, comparing the upward slopes of the regression lines with a one-tailed t-test test. Statistical significance was assumed in each comparison when $P<0.05$.

\section{Results}

\section{Patients}

Of the 30 patients allocated to each group, successful epidural blocks were performed in 24 patients in the $0.125 \%$ bupivacaine-fentanyl group, in 24 patients in the $0.25 \%$ bupivacaine group, and in 27 patients in the $0.125 \%$ bupivacaine group. These represent first-attempt success rates of $80-90 \%$ which were similar among the groups. Group I was not different from the other groups, with regards to age, weight, height and gestational age (Table I).

\section{Outcome of labour}

The durations of both the active phase of the first stage of labour and the second stage of labour were not significantly different when Group I was compared with the other groups (Table I). The durations of the epidural infusion were also not significantly different. The modes of delivery distribution, subdivided as vaginal spontaneous, vaginal assisted (forceps/vacuum) and Caesarean section, were not significantly different in either of the two comparisons (for Group I versus Group II, $P=0.2$ with power 0.89 ).

The overall Caesarean section rate was $12 \%$, compared with $20 \%$ for all deliveries at the study institution in 1989. Only one Caesarean section was performed for fetal distress, for a patient from Group I who had not reached full dilatation. The overall assisted vaginal delivery rate was $20 \%$. Fetal distress was the recorded indication for assisted vaginal delivery for one, two and two deliveries 
TABLE I Group demographic data and outcome of labour

\begin{tabular}{|c|c|c|c|}
\hline Variable & $\begin{array}{l}\text { Group I } \\
\text { B } 0.125 \%+ \\
\text { fent } 4 \mu \mathrm{g} \cdot \mathrm{ml}^{-1}\end{array}$ & $\begin{array}{l}\text { Group II } \\
\text { Bupivacaine } \\
0.25 \%\end{array}$ & $\begin{array}{l}\text { Group III } \\
\text { Bupivacaine } \\
0.125 \%\end{array}$ \\
\hline Successful (n) & $24 / 30$ & $24 / 30$ & $27 / 30$ \\
\hline Age (yr) & $26 \pm 5$ & $26 \pm 4$ & $27 \pm 4$ \\
\hline Weight (kg) & $73 \pm 9$ & $78 \pm 10$ & $76 \pm 14$ \\
\hline Height $(\mathrm{cm})$ & $164 \pm 6$ & $165 \pm 7$ & $164 \pm 8$ \\
\hline Gestation (wk) & $39.9 \pm 1.4$ & $39.7 \pm 1.4$ & $40.0 \pm 1.4$ \\
\hline \multicolumn{4}{|l|}{ Duration (min) } \\
\hline First stage (active) & $463 \pm 272$ & $448 \pm 279$ & $495 \pm 331$ \\
\hline Second stage & $95 \pm 58$ & $92 \pm 76$ & $91 \pm 76$ \\
\hline Epidural infusion & $355 \pm 207$ & $349 \pm 172$ & $364 \pm 203$ \\
\hline \multicolumn{4}{|l|}{ Mode of delivery } \\
\hline Spontaneous & $19(79 \%)$ & $15(62 \%)$ & $17(63 \%)$ \\
\hline ( $95 \%$ conf. interval) & $( \pm 16 \%)$ & $( \pm 20 \%)$ & $( \pm 19 \%)$ \\
\hline Forceps/vacuum & $2(8 \%)$ & $5(21 \%)$ & $8(30 \%)$ \\
\hline $\begin{array}{l}\text { Caesarean section } \\
\text { - before full }\end{array}$ & $3(13 \%)$ & $4(17 \%)$ & $2(7 \%)$ \\
\hline $\begin{array}{l}\text { dilatation } \\
\text { - after full }\end{array}$ & 2 & 1 & 2 \\
\hline dilatation & 1 & 3 & 0 \\
\hline
\end{tabular}

Mean \pm SD

in Groups I, Il and III respectively. In all groups, vacuum extraction accounted for about $50 \%$ of assisted deliveries. The overall spontaneous vaginal delivery rate was $68 \%$. The overall rate of spontaneous delivery with respect to vaginal deliveries alone was $77 \%$.
Quality of analgesia

Analgesia as scored on the Visual Analogue Scale was analyzed first on the basis of time relative to the test dose. Table II shows that the baseline pain levels prior to administration of epidural analgesia were not different and that all three groups achieved similar reductions in pain scores when the pain scores at time 30 minutes were compared. For the time period 30 to $300 \mathrm{~min}$, the median and the upper and lower quartiles of the summary pain scores within each group are shown in Table Il. The summary pain scores in Group I were not different from those of Group II but were lower than in Group III ( $P<$ $0.05)$. The median VAS scores from injection of the test dose, to $300 \mathrm{~min}$ are shown in Figure 1. After $90 \mathrm{~min}$, when the effect of the establishing dose in each group diminished and the effect of the infusion became more important, there was a trend for patients in Group III to score higher on the pain scale.

The level of analgesia as obtained by the Visual Analogue Score was then analyzed on the basis of time relative to full dilatation, using pain scores 30 minutes or more after the test dose. The median pain scores by group for each recording time are shown in Figure 2. The median summary pain scores for the time periods of the first stage labour ( -300 minutes to 0 minutes) and the second stage labour ( 0 minutes to 120 minutes) are shown in Table Il. Group I summary pain scores during the first stage were not different from those of Group II but were lower than those of Group III. During the second stage

TABLE II Analgesia: VAS scores and patient assessments

\begin{tabular}{|c|c|c|c|c|c|}
\hline Time/time interval & $\begin{array}{l}\text { Group I } \\
\text { B } 0.125 \%+ \\
\text { fent } 4 \mu \mathrm{g} \cdot \mathrm{ml}^{-1}\end{array}$ & $\begin{array}{l}\text { Group II } \\
\text { Bupivacaine } \\
0.25 \%\end{array}$ & $\begin{array}{l}\text { Group III } \\
\text { Bupivacaine } \\
0.125 \%\end{array}$ & $\begin{array}{l}P \\
(1-2)\end{array}$ & $\begin{array}{l}P \\
(I-3)\end{array}$ \\
\hline \multicolumn{6}{|l|}{ VAS scores } \\
\hline - Time $0 \mathrm{~min}^{*}$ & $\begin{array}{l}80 \\
(70-89.5)\end{array}$ & $\begin{array}{l}80 \\
(72.5-95)\end{array}$ & $\begin{array}{l}80 \\
(75-100)\end{array}$ & NS & NS \\
\hline - Time $30 \mathrm{~min}^{*}$ & $\begin{array}{l}0 \\
(0-15)\end{array}$ & $\begin{array}{c}5 \\
(0-20)\end{array}$ & $\begin{array}{c}0 \\
(0-15)\end{array}$ & NS & NS \\
\hline - Time $30-300 \mathrm{~min}^{*}$ & $\begin{array}{c}0 \\
(0-20)\end{array}$ & $\begin{array}{l}10 \\
(0-30)\end{array}$ & $\begin{array}{l}20 \\
(0-40)\end{array}$ & NS & $<0.05$ \\
\hline \multicolumn{6}{|l|}{ Rel. to full dilatation } \\
\hline - First stage & $\begin{array}{l}0 \\
(0-25)\end{array}$ & $\begin{array}{l}10 \\
(0-30)\end{array}$ & $\begin{array}{l}20 \\
(0-40)\end{array}$ & NS & $<0.05$ \\
\hline - Second stage & 20 & 40 & 42.5 & NS & NS \\
\hline \multirow{2}{*}{\multicolumn{6}{|c|}{$\begin{array}{l}\text { Patient assessment } \\
\text { First stage }\end{array}$}} \\
\hline & & & & & \\
\hline $\begin{array}{l}\text { - Excellent/good } \\
\text { - Fair/poor } \\
\text { Second }\end{array}$ & $\begin{array}{r}21(88 \%) \\
3(12 \%)\end{array}$ & $\begin{array}{c}22(92 \%) \\
2(8 \%)\end{array}$ & $\begin{array}{l}16(59 \%) \\
11(41 \%)\end{array}$ & NS & $<0.05$ \\
\hline - Excellent/good & $\begin{array}{r}14(64 \%) \\
8(36 \%)\end{array}$ & $\begin{array}{r}15(65 \%) \\
8(35 \%)\end{array}$ & $\begin{array}{r}17(68 \%) \\
8(32 \%)\end{array}$ & NS & NS \\
\hline
\end{tabular}

*Median and interquartile range (25-75 percentile). 


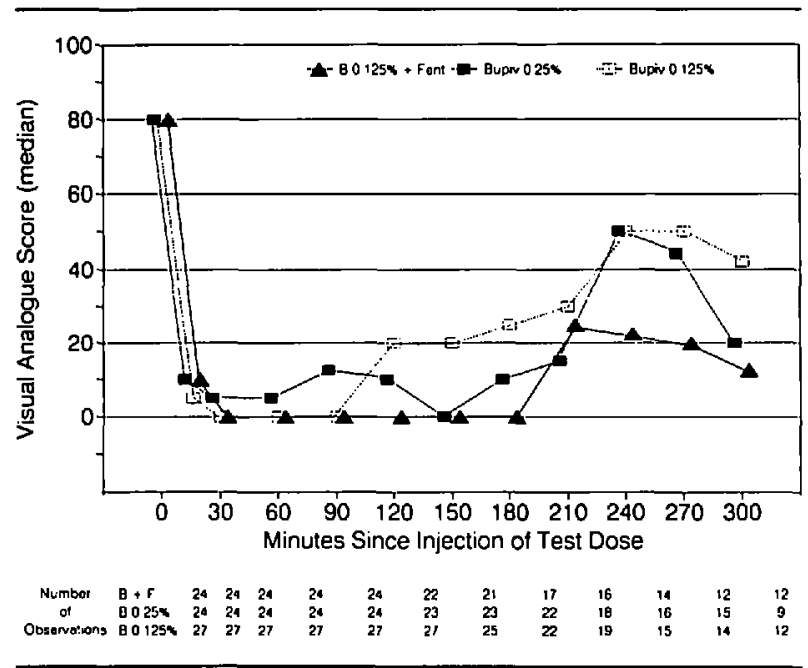

FIGURE I Median pain scores over time relative to injection of test dose.

Group I summary pain scores were not different from either Group II or Group III.

Assessment of analgesia was rated as either excellent/ good or fair/poor (Table II). In Groups I and II, the number of patients who assessed their analgesia as excellent/good during the first stage of labour was high $(90 \%)$ but fewer Group III patients $(59 \%, P<0.05)$ felt that they had received excellent/good analgesia when Groups I and III were compared. The proportion of patients assessing second stage analgesia as excellent/ good was similar $(65 \%)$ in all three groups.

\section{Drug administration}

The bupivacaine administered to patients is compared in Table III. The cumulative bupivacaine dose was less in Group I than in Group II $(P<0.001)$ but not less than in Group III. When Group I patients were compared with Group III patients, less bupivacaine was needed to supplement the basic infusion in either first or second stage. When Group I patients were compared with Group II patients, less bupivacaine supplementation was given only during the first stage of labour.

Interventions which supplemented the basic infusions or decreased the infusion rate are shown in Table III. Group I patients received fewer interventions than either Group II or Group III patients during the first stage $(P<$ 0.05 ), but not during second stage. When interventions were analyzed with respect to individual patients within groups, by comparing the proportion of patients requiring either none or a single intervention, the incidence was higher for Group I only during the first stage and only when compared with Group III $(P=0.05)$.

The majority of the interventions were $3 \mathrm{ml}$ supplementary doses of $0.25 \%$ plain bupivacaine. When motor block was judged to be excessive, the infusion rate was

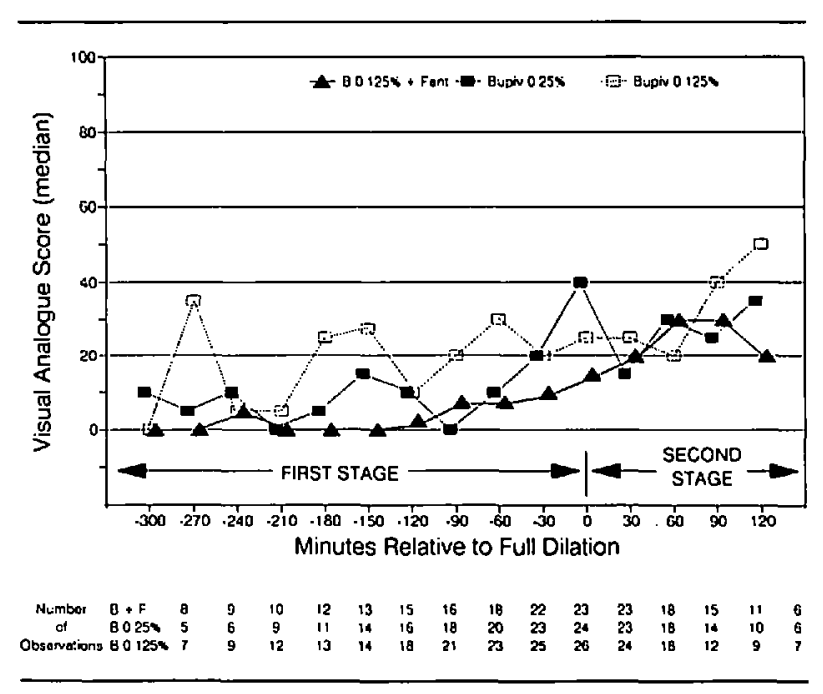

FIGURE 2 Median pain scores over time relative to full dilatation.

decreased if analgesia was adequate. During the first stage this occurred only with patients in Group II, and in only three instances. During the second stage, decreases in the infusion rate were necessary in two patients in each of Groups I and II. Carbonated lidocaine was used to provide a perineal dose for two patients in Group I, for three patients in Group II and for four patients in Group III.

\section{Motor block}

The proportion of patients who developed a motor block (score $>0$ ) are shown in Table III. The percentage of undelivered patients with motor block increased as infusion time progressed for all three groups (Figure 3 ). Yet, when Group I was compared with Group II, the rate of increase in Group I (the slope of the regression line) was significantly less $(P<0.05)$. At the time of full dilatation, the number of Group I patients who had motor block scores greater than zero was not different from the number of Group II or Group III patients who had motor blockade. However, in order to adjust for the few patients in Group Il whose infusion rate was decreased for excessive motor block according to the protocol, the number of patients who developed a motor block at any time during the first stage was analyzed. Group I patients showed a lower incidence of motor block than Group II patients $(21 \%$ versus $50 \%, P<0.05)$.

\section{Side effects/neonatal outcome variables}

The incidence of side effects was low. Nausea and emesis occurred in approximately $8-12 \%$ of patients in all groups. Urinary retention occurred in $21 \%$ of Group I patients, $29 \%$ of Group II patients and $41 \%$ of Group III patients. Patients were not specifically questioned about pruritus and no patient offered a specific complaint of feeling itchy. Clinically important hypotension requiring 
TABLE III Drug administration, interventions and motor block

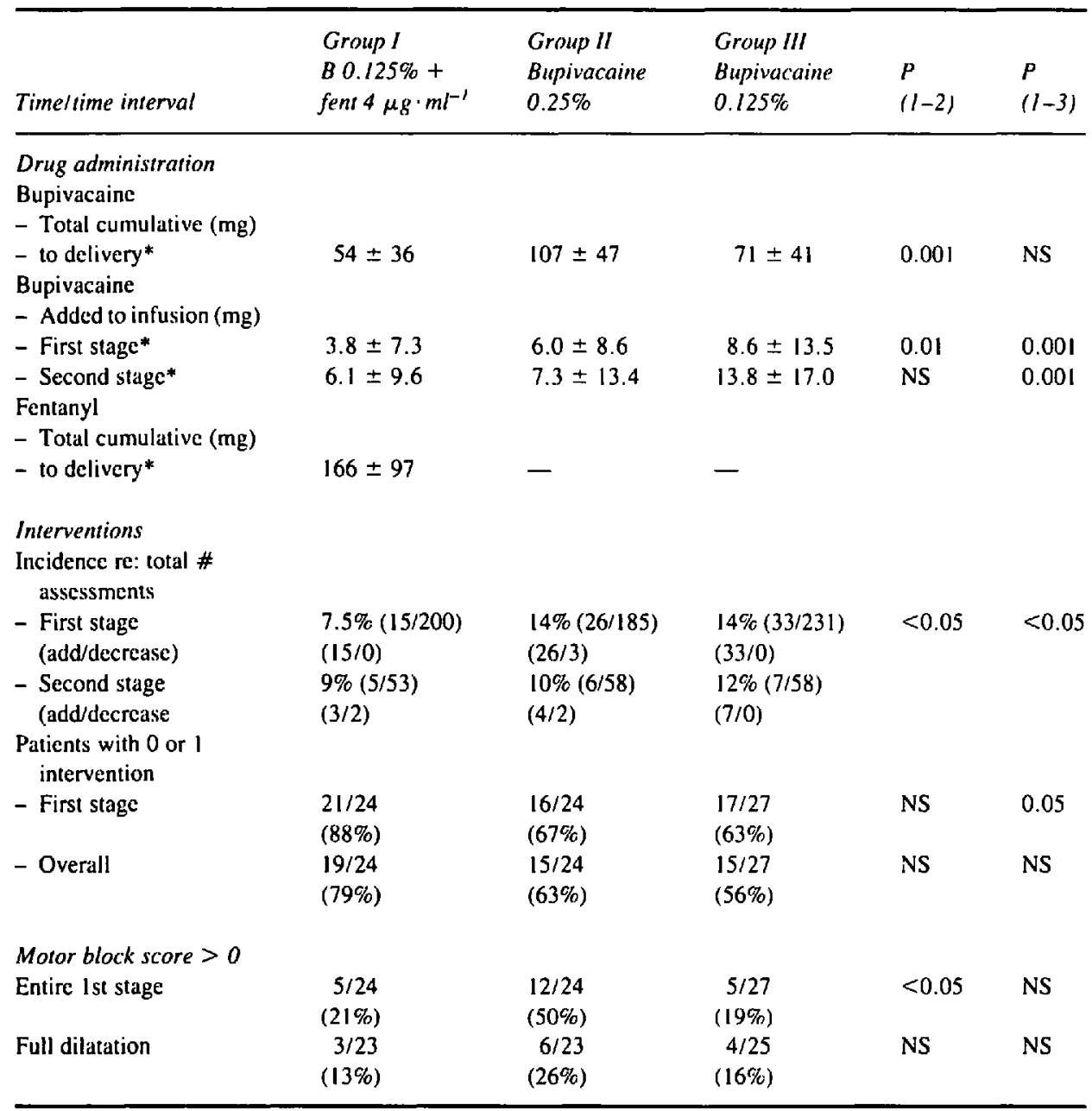

*Mean $\pm \mathrm{SD}$

treatment with a fluid bolus occurred in one Group II patient. The proportion of patients who received oxytocin augmentation was similar among the three groups (13$25 \%$ ). There were no significant differences in the neonatal outcomes (Table IV).

\section{Discussion}

The results of this investigation show that the combination of fentanyl $\left(4 \mu \mathrm{g} \cdot \mathrm{ml}^{-1}\right)$ with $0.125 \%$ bupivacaine, administered at a rate of $7 \mathrm{ml} \cdot \mathrm{hr}^{-1}$, can provide effective pain relief during the first stage of labour. The analgesia provided by the bupivacaine-fentanyl mixture was similar to that of $0.25 \%$ plain bupivacaine, while reducing the cumulative bupivacaine dose, and requiring less bupivacaine supplementation and fewer adjustments of the infusion rates. In addition, the patients who received the bupivacaine-fentanyl mixture experienced both a slower tendency to develop motor block as the infusion progressed, and fewer occurrences of motor block during the first stage of labour, compared with patients who received $0.25 \%$ bupivacaine. These data demonstrate that the bupivacaine-fentanyl mixture provided effective analgesia during the first stage of labour more than did $0.25 \%$ plain bupivacaine. Bupivacaine $0.125 \%$ was much less effective than $0.125 \%$ bupivacaine-with-fentanyl infusion in providing pain relief during the first stage despite twice as much added bupivacaine. Fentanyl is clearly an effective adjuvant to augment the analgesia provided by $0.125 \%$ bupivacaine.

Similar conclusions cannot be drawn for the second stage of labour. In the control group which received $0.25 \%$ bupivacaine, analgesia assessed by patients as excellent/good decreased from $92 \%$ during the first stage to $65 \%$ during the second stage. The result for the bupivacaine-fentanyl mixture was a similar decrease from 88 to $64 \%$. Surprisingly, $68 \%$ of patients in the $0.125 \%$ bupivacaine group assessed their second stage analgesia as excellent/good. This similar level of second stage 


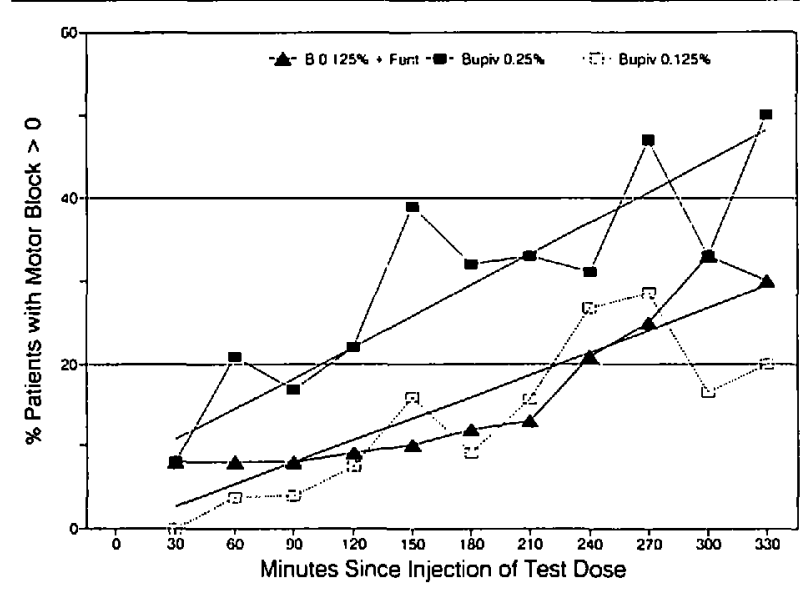

$\begin{array}{llllllllllll}\text { Numbar } 8+F & 24 & 24 & 24 & 22 & 21 & 17 & 16 & 14 & 12 & 12 & 10 \\ \text { Undodin. } 8025 \% & 24 & 24 & 24 & 23 & 23 & 22 & 18 & 16 & 15 & 9 & 6 \\ \text { Pationt3 } 80.125 \% & 27 & 27 & 27 & 27 & 25 & 22 & 19 & 15 & 14 & 12 & 10\end{array}$

FIGURE 3 Percentage of paticnts with motor block scores greater than zero versus duration of the infusion in minutes since injection of the iest dose. Multiple regression analysis for Groups I and II yielded the regression lines shown $\left(\mathrm{r}^{2}=0.87\right)$ and indicated the trend to progressive motor block over time (i.c., group-time interaction) was less for patients in Group I $(P<0.05)$.

analgesia in Group III patients might be accounted for because they received almost double the amount of supplementary bupivacaine during the second stage of labour than patients in Group I $(P<0.001)$. Groups I and II patients required similar amounts of bupivacaine supplementation during second stage. The incidence of motor block both at full dilatation and during the second stage was not different, possibly because the protocol allowed for a decrease in the infusion rate in the event of motor block. The mode of delivery distribution did not differ, given the sample size constraints. Therefore, it appears that the advantages of the bupivacaine-fentanyl mixture, which were evident during the first stage, were much less so during the second stage, particularly when the mixture was compared with bupivacaine $0.25 \%$ plain .

Chestnut et al. recently compared the analgesia result-

TABLE IV Neonatal outcome variables

\begin{tabular}{llll}
\hline & $\begin{array}{l}\text { Group I } \\
\text { B } 0.125 \%+ \\
\text { Vent } 4 \mu \mathrm{g} \cdot \mathrm{ml}^{-1}\end{array}$ & $\begin{array}{l}\text { Group II } \\
\text { Bupivacaine } \\
0.25 \%\end{array}$ & $\begin{array}{l}\text { Group III } \\
\text { Bupivacaine } \\
0.125 \%\end{array}$ \\
\hline $\begin{array}{l}\text { Weight (g)* } \\
\text { APGAR } \geq 7\end{array}$ & $3441 \pm 585$ & $3341 \pm 479$ & $3551 \pm 412$ \\
-1 min & $19 / 21(90 \%)$ & $16 / 20(80 \%)$ & $20 / 25(80 \%)$ \\
-5 min & $21 / 21(100 \%)$ & $19 / 20(95 \%)$ & $24 / 25(96 \%)$ \\
Time-to-sustained & 15 & 17.5 & 20 \\
respiration (sec) $\dagger$ & $(10-45)$ & $(5-37.5)$ & $(10-45)$ \\
\hline
\end{tabular}

*Mean \pm SD

tMedian and interquartile range (25-75 percentile). ing from continuing a bupivacaine-fentanyl mixture to delivery versus stopping at full dilatation. ${ }^{12}$ Better analgesia was found to occur when the bupivacaine-fentanyl mixture was continued throughout the second stage of labour. There are interesting similarities with regard to the present study: the summary VAS score for second stage would appear to have been in the 25 to 30 range, the patient assessment of excellent/good analgesia decreased from $90 \%$ during the first stage to $68 \%$ during the second stage, and the instrumented vaginal delivery rate was 15 to $21 \%$.

Although the bupivacaine-fentanyl mixture and the $0.25 \%$ bupivacaine plain infusions provided equivalent analgesia, neither infusion could guarantee satisfactory analgesia during the second stage of labour, given the provisions for supplementation allowed in the protocol. The somatic pain associated with delivery is probably more intense than the visceral pain associated with cervical dilatation. ${ }^{13}$ Therefore, maintaining low doses of bupivacaine to minimize motor block, although adequate for analgesia during the first stage, often results in inadequate analgesia during the second stage. Supplementation with $0.25 \%$ bupivacaine plain was provided for patients in all three groups as required in order to maintain uniformity for comparative purposes. It is possible that supplementation with fentanyl either in the bupivacainefentanyl mixture or alone may be one way to improve the performance of the mixture during the second stage. It is also possible that other potent narcotics such as sufentanil or alfentanil may prove to be more effective during the second stage for the control of pain. ${ }^{14}$

In summary, given the conditions of the present study, a mixture of bupivacaine $0.125 \%$ with fentanyl $4 \mu \mathrm{g} \cdot \mathrm{ml}^{-1}$ provided the same level of analgesia as bupivacaine $0.25 \%$ plain when both were infused at the relatively low rate of $7 \mathrm{ml} \cdot \mathrm{hr}^{-1}$. When one considers that the bupivacaine-fentanyl mixture, during the first stage of labour, required less additional bupivacaine to supplement the pre-set infusion and was associated with fewer occurrences of motor block, it would appear that the bupivacaine-fentanyl mixture offers better performance than bupivacaine $0.25 \%$ plain. However, these observations do not carry over into the second stage of labour. The challenge remains to provide for delivery the same excellent, safe analgesia which a bupivacaine-fentanyl infusion offers during labour.

\section{Acknowledgements}

I would like to thank Dr. M Stockwell for valuable assistance during the initial phases of this study, the residents of the Ottawa University Anaesthesia Program and the nurses of the Ottawa General Hospital Case Room for all their work and effort to allow me to complete the 
study, Dr. R. Nair for statistical consultation, and also Drs. D. Miller, R. Martineau and E. Crosby for helpful advice and criticism.

\section{References}

1 Matouskova A, Hanson B, Elmen $H$. Continuous mini-infusion of bupivacaine into the epidural space during labor. Part III: A clinical study of 225 parturients. Acta Obstet Gynecol Scand Suppl 1979; 83: 43-52.

2 Taylor HJC. Clinical experience with continuous epidural infusion of bupivacaine at $6 \mathrm{ml}$ per hour in obstetrics. Can Anaesth Soc J 1983; 30: 277-85.

3 Abboud TK, Afrasiabi A, Sarkis $F$ et al. Continuous infusion epidural analgesia in parturients recciving bupivacaine, chloroprocaine, or lidocaine - maternal, fetal, and neonatal effects. Anesth Analg 1983; 63: $421-8$.

4 Smedsted $K G$, Morison DH. A comparative study of continuous and intermittent epidural analgesia for labour and delivery. Can J Anaesth 1988; 35: 234-41.

5 Chestnut DH, Vandewalker GE, Owen CL, Bates JN, Choi $W W$. The influence of continuous epidural bupivacaine analgesia on the second stage of labour and method of delivery in nulliparous women. Anesthesiology 1987; 66: $774-80$.

6 Justins DM, Francis D, Houlton PG, Reynolds F. A controlled trial of extradural fentanyl in labour. $\mathrm{Br} J$ Anaesth 1982; 54; 409-14.

7 Skerman JH. Thompson BA, Goldstein MT, Jacobs MA Gupta A, Blass NH. Combined continuous cpidural fentanyl and bupivacaine in labour: a randomized study. Anesthesiology 1985; 63: A450.

8 Cohen SE, Tan S, Albright GA, Halpern J. Epidural fentanyl/bupivacaine mixtures for obstetric analgesia. Anesthesiology 1987; 67: 403-7.

9 Hunt CO, Naulty JS, Malinow AM, Datta S, Ostheimer $G W$. Epidural butorphanol-bupivacaine for analgesia during labor and delivery. Anesth Analg 1989; 68: 323-7.

10 Chestmut DH, Owen CL, Bates JN, Ostman LG, Choi WW. Geiger $M W$. Continuous infusion epidural analgesia during labour: a randomized, double-blind comparison of $0.0625 \%$ bupivacaine $/ 0.0002 \%$ fentanyl versus

$0.125 \%$ bupivacaine. Anesthesiology 1988; 68: 754-9.

11 Pagano RR. Understanding Statistics in the Bchavioral Sciences, 2nd ed. St Paul: West Publishing Co., 1986; 336-8.

12 Chestnut DH, Laszewski LJ, Pollack KL, Bates JN, Manago NK, Choi WW. Continuous epidural infusion of $0.0625 \%$ bupivacaine- $0.0002 \%$ fentanyl during the second stage of labour. Anesthesiology 1990; 72: 613-8.
13 Bonica JJ. Pain of parturition. In: Ostheimer GW (Ed.) Clinics in Anacsthesiology. London: WB Saunders Co., 1986: 4: 1-31.

14 Phillips $G$. Continuous infusion epidural analgesia in labor: the effect of adding sufentanil to $0.125 \%$ bupivacaine. Anesth Analg 1988; 67: 462--5. 